\title{
An Analysis of Coherence in Writing Essay Written by Students at Universitas Negeri Padang
}

\author{
Reni Septiwan ${ }^{1, *}$ Muhammad Al Hafizh ${ }^{1}$ \\ ${ }^{1}$ English Department, FBS UniversitasNegeri Padang, Padang, Sumatra Barat 25131, Indonesia, \\ *Corresponding author. Email: reniseptiwan059@gmail.com
}

\begin{abstract}
In writing, the students have to consider the coherence especially in writing essay. It aims to avoid misunderstanding in reading an essay. Appropriate the coherence has an important role in writing. Based on the explanation above, this study had a goal to find out the coherence in writing essay that written by English education undergraduate students at Universitas Negeri Padang. Furthermore, source of data of this study was students' essay that written as an mid exam in teaching and learning process. This study was an descriptive research to describe the coherence in writing essay that written by the students at Universitas Negeri Padang. The document was used to find out the the coherence in writing essay that written by at Universitas Negeri Padang. As a result of the study, the analysis related to the coherence in writing essay was identified and classified based on several indicators. To determine the coherence of writing essay, it consisted of repitition of key nouns, the use of consistent pronouns, the use of transition signals, and logical order.
\end{abstract}

Keywords: Coherence, Essay, Writing

\section{INTRODUCTION}

Principally, writing is one of the tools that people are using to connect. However, written communication has a smaller portion than oral communication. This phenomenon is rational since most of the correspondence between people is done orally because of its practicality. However, it does not mean that writing does not have a significant role to play in human communication. One of the proofs of the value of writing is that people can only remember the societies of the past through the writings of historical objects. In addition, people can communicate by writing without limitation of time and distance.

Regarding the important role of writing in communication, in each stage of language learning, the ability to write receives a large portion of discussion. At the university level, for example, as one of the requirements to get their undergraduate degree, every student is expected to produce an academic writing. Academic writing is a form of writing that is focused on academic subjects. It's used to write essays, journals, and articles, among other things. In addition, thesis proposals, theses, and dissertations are written in this style. Then there are a few key components of academic writing, including unity and coherence. Therefore, each academic writing is a form of writing that requires coherence.

A good academic writing is characterized by coherence. Having coherence in academic writing links all ideas about writing and links them to a single topic. It produces a writing that becomes a whole thing. Though coherence in academic writing helps the writers organize their ideas logically and smoothly. In addition, it allows readers to follow the writers' ideas on their writing. In addition to coherence, therefore, coherence is important for helping to produce good academic writing. It is therefore necessary for both writers and readers to pay attention.

Coherence is an important aspect of good academic writing. Such a component is required in order to produce coherent academic writing. Because of the presence of this element, the writing flows clearly and logically. A number of devices known as coherence 
devices are required to create a clear and logical flow. Thus, the existence of coherence devices is required to achieve coherence in academic writing.

Coherence is required for good academic writing. This component assists writers in logically and smoothly organizing their ideas. Furthermore, it makes it easier for the teacher to follow the writers' ideas in their writing. A coherent text can aid readers in understanding the writers' purpose and line of thought [5]. Also, a coherent paper allows readers to move smoothly from beginning to end. The smooth movement and clear relationship between and among sentences and paragraphs in a paper or academic writing assist readers in understanding and following the writer's ideas from beginning to end [6]. This ease is achieved in coherent academic writing because it is the result of connecting information in the writing so that the connections made in the writer's mind are visible to the reader [17]. In other words, Graduate Writing Centre claims to be starting a chain. A chain requires a number of devices known as coherence devices to be formed.

Coherence devices are words and phrases that writers can use to connect sentences and paragraphs and create a smooth flow of ideas. Coherence devices, in other words, are devices used in writing to achieve a coherent paragraph or writing. To make a paragraph sound choppy, (rough and interrupted) [14]. Some devices are required to make it coherent. As a result, coherence devices are required.

To achieve coherence in writing, a variety of coherence devices can be used. There are three main ways for writers to connect sentences within paragraphs and across paragraph boundaries. They are using connective words and phrases; referring to earlier words and phrases (by repitition, through synonyms, and through pronouns); and arranging sentences into structural patterns, including the proper ordering of old and new information [3]. Furthermore, coherence devices are classified into four types: point of view, pronoun reference (number or gender), content words (repetition of key ideas), and transitions [10]. There are four ways to achieve coherence in writing [13], as stated by Daiker et al and Leonhard. They are repeating key nouns, using consistent pronouns, using transition signals to link ideas, and arranging ideas in logical order.
The theory of Oshima and Hogue [13], the four ways to achieve coherence in writing; repeating key nouns, using consistent pronouns, using transtition signals to link ideas, and arranging ideas in logical order, is applied in this research. These four indicators are used to assess the coherence of the students' writing. Furthermore, the score of coherence of their writing, which is made in the form of a soring rubric, is derived from these indicators.

Regarding to the previous paragraph, at the university level, for example, as one of the requirements to get their undergraduate degree, every student is required to produce an academic writing. In other words, a student's intellectuality can only be acknowledged if he or she is able to produce academic writing. In addition, they must also comply with the current grammar and writing mechanisms, which should not cause difficulties when they communicate orally. The problem is much worse when they are asked to write academic writing.

For example, in writing English text, they not only face problems as described above, the lack of vocabulary also affects their writing. Nonetheless, lack of vocabulary should not be a big problem for students of the English Department since they already have a good range of words for a simple writing process. The exact problem is related to the coherence in their writing. In academic writing especially writing an essay requires and coherence. The students of the English Department of Universitas Negeri Padang are required to write an essay to fulfill their teaching learning process. However, it is not easy for them to write a coherent in their essay. In fact, they face number of problems. These problems might be caused by a number of reason. Therefore, it is important to be researched.

There are a variety of coherent writing problems faced by the students in the background of the study of research proposal. Dealing with coherence, students face many problems. While writing a paragraph, there are four major problems with unity faced by the learners [7]. They are an inaccurate topic sentence, a point of support that is unstated or ambiguous, a missing transitional word, and digressive details. Another problem, instead, is adding more than one idea. Introducing more than one idea in a paragraph breaks the paragraph's coherence. Only one main idea is mentioned in all the sentences in a unified paragraph 
[12]. Finally, the form of the general statement and the thesis statement are not shown. The structure of the general statement and the thesis statement are two important elements that, in addition to a single topic, contribute to the unified background section of thesis writing of students. One type of general statement writing that moves from general statements to more specific ones is the background section of the thesis [16]. In addition, they claim that the form of this type of writing is ended by a broader statement i.e. to state thesis statement.

As far as coherence is concerned, the first problem is not key nouns or the repetition of key nouns. It happens when key nouns are missing or are not repeated. The second one is lacking and the use of pronouns is inappropriate. It occurs inappropriately due to the absence or use of pronouns. Missing and inappropriate use of transition signals is another problem. It occurs since there is a lack of relation with the ideas in the essay and between them. The next problem is lacking and the use of logical order is inappropriate. It happens because of the lack of or inappropriate use of writing organization.

The students face a number of problems in writing a coherent essay. These problems could be caused by a number of factors. The first factor is the lack of knowledge, which refers to the basic competence of students to possess in order to create a coherent essay. The second factor is the lack of writing skills in paragraph. Paragraph writing skills play an important role in building a coherent essay. In addition, essay consists of several paragraphs, which are very important to ensure that the written ideas are well-organised. The problem occurs when the students are unable to organize their ideas due to a lack of writing skills they have.

The important role of coherence has attracted a number of scholars to do a research on it. Furthermore, Auli [1] did the study on unity and coherence on the naional scene column in the Jakarta post. Those previous studies provide an insight that another academic writing type, such as a argumentative paragraph, parahraph writing, and composing paragraph. might have an unity and coherence that are necessary to be studied. So, studying a coherence in the essay writing is a gap that can be filled in by this present study.

\section{METHODS}

This research was categorized as a descriptive research. Concerning with this research, the current research was considered descriptive since it is intended to describe and interpret the level of coherence in the essay writing written by the fourth year English Department students of Universitas Negeri Padang. The data were taken from the analysis format consists of indicators and sub indicators in coherence in the essay writing in students' essay.

This study classified the coherence in the essay writing. After displaying and explaining the data, the conclusion was made. The conclusion explained clearly about how coherence in the essay writing, coherence in the essay writing based on the raters and comments given by them. It interpreted how the coherence in the essay writing were considered problematic.

\section{RESULTS AND DISCUSSION}

From the analysis of this study. There were four results that found in this study. They were repitition of key nouns, the use of consistent pronouns, the use of transition signals, and logical order. The explanation can be seen as follow.

\section{Datum 1}

Nowadays, we know that almost everyone use social $\underline{\text { media }}$ whether it's from young or old people. Social $\underline{\text { media }}$ also become to a communication place. You can know what's happening in the world. Social media make many people get negative impacts because of you can search what you wanna search there but beside of that social media give good impacts too for public and social media make people dependent on the internet.

The key nouns in the example above are social media. These key nouns are repeated several times to connect the ideas between and within sentences in the paragraph and, in longer essays, from one paragraph to the next.

Besides, repetition of key nouns is one way to achieve coherence in writing. The repetition of key nouns is the repetition of main words or nouns found in the topic sentence of a paragraph. The simplest way to achieve coherence is to repeat key nouns frequently 
within a paragraph [13]. To make a paragraph or an entire piece of writing more coherent, the key nouns must be repeated.

When the meaning is unclear, a key noun should be repeated rather than a pronoun. Repetition is required to make it clear. Repetition of key words in a paragraph is required to keep the reader focused on the topic [4]. In line with Oshima and Hogue and Folse et al, Zemach and Rumisek [13] [4] [20] state that repeating important words and phrases in an essay is one way to connect ideas and help the reader remember the main point in the text. However, if the writers are concerned about using the same key words over and over again, which may sound too repetitive, they can replace them with pronouns or similar words. When the writers do not want to repeat the key nouns, they can use synonyms of expressions with the same meaning [13]. In other words, this is referred to as key noun substitutions. In other words, these are known as key noun substitutes. The most obvious link is the repetition of key nouns, which can sometimes take the form of identical words, variant forms of the same word, and synonymous terms [8].

Furthermore, repetition helps readers stay focused on the ideas. Repetition of key words or phrases helps connect the idea(s) and keeps the reader focused on the essay [15]. In short, repetition of key nouns, words, or phrases, in addition to the use of pronouns, is one way to achieve coherent writing.

Furthermore, the using consistent pronoun was one of indicator in coherencing a paragraph in writing essay. The use of consistent pronouns is demonstrated in the example below.

\section{Datum 2}

As for the negative effects of social media, such as the number of teenagers or social media users who are addicted to forgetting time to rest, they can spend a long time and are not aware that they have damaged their own health, especially the health of their eyes and hands.

The pronouns they and their refer to the preceding noun, the number of teenagers, in the text. The presence of these pronouns keeps the paragraph's focus on the teenagers and makes the paragraph more cohesive.
Afterward, using consistent pronouns is another way to achieve coherence in writing. A pronoun is defined as "a word used instead of and to indicate a noun already mentioned or known, especially to avoid repetition" [2]. A pronoun (he, she, it, they, and so on) replaces a noun (a person, place, thing, or idea) or a noun phrase (several words that refer to a person, place, thing, or idea) [20]. A pronoun is clearly a word that is used to replace a noun or noun phrase. It can be used to connect sentences by referring back to nouns, i.e. preceding nouns and pronouns. Furthermore, it helps in the creation of easy-to-read paragraphs by avoiding unnecessary repetition.

Consistent pronouns should be used as one of the coherence devices. They must be used consistently by writers when writing. When using pronouns, writers must ensure that the same person and number are used throughout the paragraph [13]. They should not change the pronouns or point of view, for example, from you to he or she (person change) or from he to they (singular to plural and vice versa) (change of number). On the other hand, if the writers change the pronouns or do not use them consistently, the meaning and grammatical structure of the sentence may change, leaving the readers confused. As a result, it is important to use consistent pronouns to make the paragraph easy to read.

Writers must understand the different types of pronouns in order to use them consistently. There are eight kinds of pronouns [11]. (1) Personal pronouns are words that refer to a specific person, place, or thing and change form to indicate person, number, case, and gender. They are classified into three types: subjective personal pronouns, objective personal pronouns, and possessive personal pronouns. They, them, and their are examples of these pronouns. (2) Demonstrative pronouns, which point to and identify a noun or a pronoun, such as this, that, these, and those. (3) Interrogative pronouns are used to ask who, which, and what questions. (4) Relative pronouns, such as who, whom, which, are used to link one phrase or clause to another. (Indefinite pronouns refer to an identifiable but unspecified person or thing, such as all, another, or everyone). (6) Reflexive pronouns, such as myself, himself, or themselves, are used to refer back to the subject of the clause or sentence. (7) Intensive pronouns, pronouns that are used to emphasize their antecendants, such as herself or ourselves. (8) Reciprocal pronouns are used to refer to a mutual group of people. They are each 
other and one to another. In short, understanding the different types of pronouns helps readers to use them consistently.

Pronouns are words that are used to replace nouns and noun phrases. They must be used consistently when writing. Using consistent pronouns helps writers in producing coherent writing. As a result, they must be familiar with a variety of pronouns and understand how to use them.

Moreover, the use of transition signals or transitional expression was indicated as one of indicator in the coherence a paragraph in writing essay. For example,

\section{Datum 3}

On the one hand, people prefer offline shopping because they don't need to wait after the purchase. Shipping to other city might take more than two days and sometime there is delay in delivery which is the most common problem in delivery. Also, the shipping cost might be higher than the product price. If there is problem with things that you bought, return process could be complicated. Sometimes you need to prove it with photos or videos so they could process the return or refund. In addition, the risk of fraud is higher on online shopping. For example, fake online store or website, goods or stuff that different from the picture, credit card scams, hacking, and other common types of scams.

The previous example demonstrates the use of transition signals in a paragraph. In the paragraph, a number of transition signals, on the one hand, also, in addition, and for example, are used to signal the connection of ideas. The use of transition signals improves the paragraph's coherence.

Then, the use of transition signals or transitional expressions is the next way to achieve coherence in writing. Transitional espressions are words and phrases used by writers to signal connections between their ideas [18]. In addition, as "words and phrases that connect the idea in one sentence with the idea in another sentence" [13]. Clearly, transition signals are words and phrases used to connect ideas from one sentence to the next. Thus, transition signals are required in writing to signal the connection of ideas.
Transition signals are necessary in writing. They entice readers to follow the writers' thought process. The writers inform the readers about how they relate between and among their ideas on their writing through these transitions. In other words, they serve as a guide to help readers move from one idea to the next. Transition signals are like traffic signs that tell readers when to go forward, turn around, slow down, and stop [13]. In other words, transition signals tell readers when to give a similar idea, an opposite idea, an example, a result, or a conclusion. As a result, these transition signals should be paid attention.

There are several types of transition signals to which you should pay attention when writing. [12] classify them into three groups based on grammatical function. The first category is sentence connectors. It includes transition phrases such as in addition, on the other hand, and ad conjunctive adverbs such as furthermore, therefore. The second category is clause connectors, which include coordinating conjunctions like but and or as well as subordinating conjunctions like because and although. The final group is a mixed group known as others. It includes adjectives like extra, prepositions like despite, and nou like example.

Furthermore, there were categorized transition signals based on their meaning [13]. They are used to: (1) introduce an additional idea; additionally, besides, (2) introduce an opposite idea or contrast; in contrast, however, (3) introduce a choice or an alternative otherwise, unless, (4) introduce a restatement or explanation, in fact, (5) list in order or show time sequences first, next, etc. (6) Introduce an example, for example, (7) Introduce a conclusion or summary in brief, in conclusion (*) As a result, introduce a result. Understanding the various types of transition signals help writers to use them in their writing.

Regarding to the use of various types of transition signals, there are some principles that must be followed when using various types of transition signals. There are three key principles that writers should follow when dealing with transition signals [17]. First, it is suggested that the writers select the transition that best matches the rhetorical strategy. When they want to contrast two ideas in a paragraph, they should use contrastive transition signals such as while, on the other hand, however, or other. Second, they must avoid using overusing transitions. Writers should use transition 
signals only when they help readers follow their ideas, otherwise they can be distracting rather than helpful [13]. Finally, transitions between paragraphs should be provided. These transitions connect one paragraph to another. Thus, when using transition signals, the writer should select the appropriate ones and avoid overusing them.

Transition signals lead readers to follow the flow of thought of the writers on their writing by using words and phrases to signal connections among ideas. They can be used to connect clauses, sentences, and paragraphs. Their presence in writing describes the connection between the ideas in a sentence, between sentences in a paragraph, and between paragraphs in a piece of writing. This connection then contributes to coherent writing.

The last, logical order was one of indicators to know the coherence in writing essay. A paragraph in the following example shows the use of one of the logical orders, logical division of ideas.

\section{Datum 4}

Online shopping is really popular nowadays. Many people use it because it's a good choice to purchase things that people want or need with cheaper price compare to the offline store. You can find the online stores with the best reputations by seeing the stars and reading the reviews given from other shoppers. You can also buy items from another country as it also provides worldwide shipping. Just by clicks and taps, you can order anything you want, then it directly arrive to your home, and even you can pay it after you check your order. However, some people find it inconvenient to shop online when they face delivery problems and delay, or fraud that might happen while shopping online; still, others think that it also has several benefits for shopping.

The previous paragraph about online shopping demonstrates the use of logical order, or the logical division of ideas. The topic of online shopping is divided into two parts, each with its advantages and disadvantages. It discusses advantages of online shopping first, and then its disadvantages of online shopping second. The use of this logical order allows readers to easily grasp the writers' writing pattern of developing their ideas.
Another way of producing coherent writing is to use logical order. It is putting the sentence in a logical order. Writers organize their paragraphs or writing in certain patterns so that they are easy to recognize and provide the readers with a sense of logical movement as well as order of ideas in writing [19]. It assists not only writers in organizing their ideas, but also readers in comprehending the patterns used by writers in developing their ideas. As a result, they must both comprehend it. There are several logical orders that writers can use to organize their ideas in writing.

There are five patterns of paragraph organization: description, time order (process and narrative paragraph), logical division of ideas, comparison and contrast, order of importance, and a sixth pattern, combination paragraphs [13]. Next, there are nine patterns of paragraph development, five of which are identical to the first four of Hogue's, while the others, exemplification, cause and effect, definition, and argument, are clearly different [9]. In addition, there are some common logical orders in English. There are several types of logical order in English; chronological order i.e. order by time - a sequence of events or steps in a process, logical division of ideas - a topic is discussed into parts, and each part is discussed separately, and comparison and contrast - the similarities and or differences between two or more items are discussed [13]. Knowing these, then, helps the writers to use them appropriately.

There are a few things to keep in mind when employing logical order. The choice of one type of logical order over another, is determined by the topic and purpose of the writers [13]. The type of logical order used is influenced by the topic to write about and the goal to achieve. They also state that writers may use two or more different logical orders within the same paragraph as long as they are logical to the readers and are written in English. Furthermore, When it comes to sequencing information to achieve coherence, writers must consider genre and text construction because different genres necessitate different writing [5]. In other words, a different text or genre necessitates a different logical order. To summarize, in order to use an appropriate logical order in writing, writers must consider the topic, purpose, and genres of writing.

To conclude, in order to achieve a coherent paragraph or writing, writers must arrange their 
sentences or ideas in a logical order. The use of logical order assists writers in organizing their ideas while also assisting readers in understanding the patterns used by writers in developing their ideas. To achieve coherence in writing, a variety of logical orders can be used, and their application is determined by the topic, purpose, and genre of writing.

The theory of Oshima and Hogue [13], the four ways to achieve coherence in writing; repeating key nouns, using consistent pronouns, using transtition signals to link ideas, and arranging ideas in logical order, is applied in this research. These four indicators are used to assess the coherence of the students' writing. Furthermore, the score of coherence of their writing, which is made in the form of a soring rubric, is derived from these indicators.

In conclusion, it can be understood that the students had good ability in using coherence in writing essay. The students have known how to use the coherence properly. Therefore, the students had good essay and it was easier to read by the readers.

\section{CONCLUSION}

From the results above, there were four indicators in using coherence in writing essay. It was known that the students could use the coherence in each paragraph of essay properly. It consisted of repitition of key nouns, the use of consistent pronouns, the use of transition signals, and logical order.

\section{ACKNOWLEDGMENT}

I would like to thank to Allah SWT who blessing me in writing this paper. I also would like to thank to English Education Study Program, Univeristas Negeri Padang. The warmest appreciation is given to my supervisor Dr. Muhammad Al Hafizh, S.S., M.A. for guiding me with constructive advices to finish this paper. This paper is far from being perfect, but I hope this paper will be useful for the development of education especially for other researchers. Moreover, advices and critics from the readers will be much appreciated.

\section{REFERENCES}

[1] Auli, Z.N. (2013). An Analysis of Unity and
Coherence on the National Scene Column in the Jakrta Post on $20^{\text {th }}$ March- $2^{\text {nd }}$ April 2012. Undergraduate thesis. Universitas Muhammadiyah Gresik.

[2] Burchfield, R.W. (2000). The New Fowler's Modern English Usage. Rev. $3^{\text {rd }}$ Ed. New York: Oxford University Press Inc.

[3] Daiker, D. A., Kerek, A., Morenberg, M., Sommers, J. (1994). The Writer's Options: Combining to Composing. $5^{\text {th }}$ Ed. New York: Harper Collins Colege Publisher.

[4] Folse, K. S., Solomon E. V., \& Clabeaux, D. (2009). Great Writing 3: From Great Paragraphs to Great Essays. 2 ${ }^{\text {nd }}$ Ed. Boston: Cengage Learning.

[5] Harmer, J. (2007). How to Teach Writing. Essex: Pearson Educational Limited.

[6] Henning. T. B. (2008). Revising for Coherence \& Unity. Indiana University Writing Centre. Retrieved January 7, 2016, from http:/liberalarts.iupui.edu/uwc/uploads/docs/Coh erence+and+Unity.pdf

[7] Juzwiak, C. (2009). Stepping Stones: A Guided Approach to Writing Sentences and Paragraphs. Boston: Bedford/St.Martin's.

[8] Kane, T. S. (2000). The Oxford Essential Guide to Writing. New York: Oxford University Press.

[9] Langan, J. (2010). Exploring Writing: Sentences and Paragraphs. $2^{\text {nd }}$ Ed. New York: Mc Graw Hill.

[10] Leonhard, B. H. (2002). Discoveries in Academic Writing. Boston: Heinle \& Heinle.

[11] MacFayden, H. (2007a). Pronouns. Retrieved May 3, 2016, from http://grammar.ccc.comment.edu/grammar/pron ouns1.html

[12] Oshima, A. \& Hogue, A. (1997). Introduction to Academic English. $2^{\text {nd }}$ Ed. New York: Addison Wesley Longman. 
[13] Oshima, A. \& Hogue, A. (2006). Writing Academic English. New York: Pearson Longman.

[14] Reid, J. M. (1994). The Process of Paragraph Writing. $2^{\text {nd }}$ Ed. New Jersey. Prentice-Hall, Inc.

[15] Sherman, D., Slawson, J., Whitton, N., Wiemelt, J. (2011). Coherence. Southeastern Writing Center Journal. Retrieved March 2, 2016, from http://www.southeastern.edu/acad.../writing_cen ter/.../pdf.../coherence

[16] Swales, J.M. \& Feak, C.B. (20212). Academic Writing for Graduate Students: Essential Tasks and Skills. $3^{\text {rd }}$ Ed.Ann Arbor. The University of Michigan Press.

[17] The Graduate Writing Centre. (2010). Achieving Coherence in Academic Writing. Retrieved March 30, 2016, from http://pwr.la.psu.edu/ resources/ graduate-writing-center/ handsout/ handsout $1 /$ Coherence $\% 20$ in $\% 20$ Academic $\% 20$ Writin\%20Fall\%202010.pdf

[18] Troyka, L. Q. \& Hesse, D. (2009). Handbook for Writers. $9^{\text {th }}$ Ed. New Jersey: Pearson Education

[19] Wyrick, . (2011). Steps to Writing Well. $11^{\text {th }}$ Ed. Boston: Wadsworth Cengage Learning

[20] Zemach, D. E. \& Rumisek, L. A. (2005). Academic Writing: from Paragraph to Essay. Oxford : Macmillan. 